\title{
Aspectos fisiopatológicos da disbiose intestinal em estudantes de uma instituição de ensino privada do Distrito Federal
}

\author{
Physiopathological aspects of intestinal dysbiosis in students from a private education \\ institution in the Federal District
}
Aspectos fisiopatológicos de la disbiosis intestinal en estudiantes de una institución educativa privada del Distrito Federal

Giulia Causin Vieira ${ }^{1 *}$, Fabíola Fernandes dos Santos Castro.

\begin{abstract}
RESUMO
Objetivo: Avaliar os aspectos fisiopatológicos da disbiose intestinal, bem como estabelecer a prevalência desta nos indivíduos participantes. Métodos: Trata-se de um estudo descritivo transversal, realizado por meio da aplicação individual do Questionário de Rastreamento Metabólico à 300 estudantes de uma instituição de ensino privada do Distrito Federal, durante o mês de fevereiro de 2020. Dados estatísticos foram destacados para sintomas gastrointestinais e para as demais seções do questionário, afim de avaliar a presença da disbiose intestinal e seus aspectos fisiopatológicos. Para análise descritiva dos dados foram estabelecidas prevalências, frequências absolutas e relativas. Resultados: $68 \%$ dos participantes relataram sintomas de hipersensibilidade e $29 \%$ apresentaram disbiose intestinal, sendo que os portadores dessa desordem exibiram de forma significativa sintomas característicos de renite alérgica $(49,43 \%)$, desequilíbrios emocionais $(48,28 \%)$, mentais $(47,13 \%)$, falta de energia física $(29,89 \%)$ e disfunções cutâneas $(21,84 \%)$, ressaltando a influência da microbiota intestinal sobre o sistema imunológico e neuroendócrino. Conclusão: A prevalência de disbiose intestinal é baixa, mas os participantes apresentaram de forma intensa quadros de alergia, ansiedade, irritabilidade, memória ruim, fadiga, queda de cabelo e acne. Portanto, a associação entre disbiose intestinal e distúrbios extra intestinais é de extrema importância para um diagnóstico e terapêutica potencial das desordens abordadas.
\end{abstract}

Palavras-chave: Disbiose intestinal, Hipersensibilidade, Microbiota intestinal.

\begin{abstract}
Objective: To evaluate the pathophysiological aspects of intestinal dysbiosis, as well as to establish its prevalence in participating individuals. Methods: This is a cross-sectional descriptive study, carried out through the individual application of the Metabolic Screening Questionnaire to 300 students from a private educational institution in the Federal District during February 2020. Statistical data were highlighted for gastrointestinal symptoms and for the other sections of the questionnaire, in order to assess the presence of intestinal dysbiosis and its pathophysiological aspects. For descriptive analysis of the data, prevalences, absolute and relative frequencies were established. Results: $68 \%$ of the participants had symptoms of hypersensitivity and $29 \%$ had intestinal dysbiosis, and the carriers of this disorder significantly exhibited symptoms characteristic of allergic rhinitis (49.43\%), emotional imbalances (48.28\%), mental ( $47.13 \%)$, lack of physical energy (29.89\%) and skin dysfunction (21.84\%), highlighting the influence of the intestinal microbiota on the immune and neuroendocrine system. Conclusion: The prevalence of intestinal dysbiosis is low, but the participants had severe symptoms of allergy, anxiety, irritability, poor memory, fatigue, hair loss and acne. Therefore, the association between intestinal dysbiosis and extra-intestinal disorders is extremely important for a diagnosis and potential treatment of the disorders addressed.
\end{abstract}

Keywords: Intestinal dysbiosis, Hypersensitivity, Intestinal microbiota.

${ }^{1}$ Centro Universitário de Brasília (UniCEUB), Brasília - DF. *E-mail: giulia.causin@sempreceub.com 


\section{RESUMEN}

Objetivo: Evaluar los aspectos fisiopatológicos de la disbiosis intestinal, así como establecer su prevalencia en los individuos participantes. Métodos: Se trata de un estudio descriptivo transversal, realizado mediante la aplicación individual del Cuestionario de Cribado Metabólico a 300 estudiantes de una institución educativa privada del Distrito Federal durante febrero de 2020. Se destacaron datos estadísticos para síntomas gastrointestinales y para el resto de apartados del cuestionario, con el fin de evaluar la presencia de disbiosis intestinal y sus aspectos fisiopatológicos. Para el análisis descriptivo de los datos se establecieron prevalencias, frecuencias absolutas y relativas. Resultados: El $68 \%$ de los participantes presenta síntomas de hipersensibilidad y el $29 \%$ disbiosis intestinal, y los portadores de este trastorno exhibieron de manera significativa síntomas característicos de rinitis alérgica $(49,43 \%)$, desequilibrios emocionales $(48,28 \%)$, mentales $(47,13 \%)$, falta de energía física $(29,89 \%)$ y disfunción cutánea $(21,84 \%)$, destacando la influencia de la microbiota intestinal sobre el sistema inmunológico y neuroendocrino. Conclusión: La prevalencia de disbiosis intestinal es baja, pero los participantes presentaban síntomas severos de alergia, ansiedad, irritabilidad, mala memoria, fatiga, caída del cabello y acné. Por lo tanto, la asociación entre disbiosis intestinal y trastornos extra-intestinales es de suma importancia para el diagnóstico y posible tratamiento de los trastornos abordados.

Palabras clave: Disbiosis intestinal, Hipersensibilidad, Microbiota intestinal.

\section{INTRODUÇÃO}

O intestino humano é considerado um órgão complexo por suas funções, como a digestão, absorção de nutrientes e síntese de determinadas vitaminas, as quais são realizadas de forma eficaz graças a presença das inúmeras espécies bacterianas que existem no seu interior. Postulou-se que o trato intestinal possui a população de bactérias mais abundante e diversificada do corpo humano. Nesse contexto, surgiu o conceito de ecossistema intestinal, considerando a importância da atividade de regulação qualitativa da microbiota intestinal e as interações às quais é submetida pelos microrganismos que coexistem nela, substratos digestivos, epitélio da mucosa intestinal e sistema imunológico (OLIVARES M, et al., 2013; JANDHYALA SM, et al., 2015).

A microbiota intestinal consiste em quatro filos ou divisões bacterianas: Firmicutes, Bacteriodetes, Actinobacteria e Proteobacteria. Fungos e Archaea também podem ser residentes, mas sua população corresponde a $1 \%$ do total. A maioria da microbiota corresponde a Firmicutes e Bacteroidetes, que representam entre 90 e $99 \%$ em humanos. Estima-se que o número de espécies bacterianas individuais no trato digestivo varia em torno de 15.000 a mais de 35.000 espécies, no entanto, o conteúdo do microbioma é enormemente diversificado de uma pessoa para outra, além do fato que a microbiota intestinal é extremamente dinâmica e pode ser influenciada por fatores exógenos e endógenos (QIN J, et al., 2010; HUGON P, et al., 2015; JANDHYALA SM, et al., 2015).

A microbiota tem demonstrado interagir com o hospedeiro de forma simbiótica, exercendo três funções principais: metabólica, trófica e protetora. A função metabólica é caracterizada pela produção de vitaminas $\mathrm{B} 12$ e K, e principalmente pelo processo de fermentação dos substratos não digeríveis dos alimento, sendo o processo de fermentação dos carboidratos a maior fonte de energia, com consequente produção de ácidos graxos de cadeia curta (AGCC). Já a função trófica é represetanda pela atividade dos AGCC na mucosa intestinal, os quais estimulam o desenvolvimento e diferenciação das células epiteliais, bem como auxiliam na prevenção de patologias do cólon. Por último, a atividade protetora é excercida pela microbiota comensal, que compete com germes patogênicos pelos locais de adesão e impede a sua penetração nas células epiteliais da mucosa intestinal (GUARNER F, et al., 2012; CASTAÑEDA C, 2018).

O equilíbrio homeostático da microflora intestinal é extremamente benéfico para o hospedeiro, no entanto, se houver alteração na composição microbiana que cause um desequilíbrio drástico entre as bactérias, o intestino se torna vulnerável ao insulto patogênico. Esse desequilíbrio é denominado disbiose, definido como um distúrbio na homeostase da microbiota intestinal devido a um desequilíbrio na própria composição, 
alterações nas atividades metabólicas bacterianas ou na distribuição local. A disbiose pode, além disso, ser dividida em três tipos, devido a sua causa: 1. Perda de bactérias benéficas, 2. Crescimento excessivo de bactérias potencialmente patogênicas e 3. Perda da diversidade bacteriana geral (KNIGHTS D, et al., 2013).

A disbiose intestinal ocorre principalmente quando o indivíduo entra em contato com uma grande quantidade de bactérias patogênicas, faz consumo excessivo de alimentos crus, de laxantes e até mesmo de antibióticos (PAIXÃO LA e CASTRO FFS, 2016).

Esse desequilíbrio no microbioma natural pode causar a perda dos efeitos imunológicos normais, que regulam a mucosa local, ocasionando um número significativo de patologias inflamatórias. Um dos mecanismos essenciais para a regulação adequada do sistema imune e estímulo da tolerância imunológica é conseguir uma homeostase adequada no decorrer da colonização do trato gastrintestinal (FRANCINO M, 2014).

O intestino possui estreita ligação com o cérebro, sendo a microbiota intestinal considerada de extrema importância para o diálogo que existe no eixo cérebro-intestino, devido ao fato que os microrganismos comensais exercem influência tanto sobre o sistema nervoso entérico, quanto sobre o sistema nervoso central. A alteração no microbioma intestinal pode levar ao desequilíbrio deste eixo, acarretando em patologias de caráter inflamatório, perturbações no comportamento alimentar, como obesidade e anorexia, alterações no humor, depressão, ansiedade e perturbações do espectro do autismo (FORSYTHE P, et al., 2010; CRYAN J e O'MAHONY S, 2011).

Além disso, há a ligação entre o microbioma intestinal com a pele, devido aos microrganismos presentes no trato gastrintestinal influenciarem a saúde do órgão em questão, através do eixo cérebro-intestino, podendo estar associado a desordens, como a psoríase, acne, rosácea, eczema e envelhecimento prematuro (BOWE W e LOBERG K, 2018).

Devido aos fatos supracitados, a disbiose é considerada um distúrbio sério, consequente dos maus hábitos mantidos pela maioria dos indivíduos nos dias atuais, e seu diagnóstico é precisamente clínico, sendo avaliados sinais e sintomas característicos de desordens gastrintestinais, como cólicas, diarreia, gases e prisão de ventre constantes, além dos sintomas que se manifestam nos outros sistemas do corpo humano, os quais possuem estreita ligação com a microbiota intestinal, sendo considerado cada vez mais importante no diagnóstico de vários estados patológicos, como depressão, letargia, mudanças de humor, fadiga e artrite reumatoide (LOPES CLR, et al., 2017; PEREIRA IG e FERRAZ IAR, 2017).

Portanto, o presente estudo tem como objetivo avaliar os aspectos fisiopatológicos da disbiose através da aplicação do Questionário de Rastreamento Metabólico (QRM) intestinal a estudantes de uma instituição de ensino superior privada, bem como estabelecer a prevalência desta nos indivíduos em questão e analisar os sinais e sintomas por eles apresentados correlacionando-os com a referida desordem.

\section{MÉTODOS}

O presente trabalho refere-se a um estudo descritivo transversal, com abordagem quantitativa, realizado por meio da aplicação individual do QRM do Centro Brasileiro de Nutrição Funcional (Dados Suplementar). O questionário foi aplicado de forma presencial a 300 estudantes de uma universidade privada do Distrito Federal durante o mês de fevereiro de 2020.

Participaram da pesquisa estudantes de ambos os sexos, com idade igual ou superior a 18 anos, que se propuseram a responder o questionário de forma voluntária. Foram excluídos da pesquisa os indivíduos que não estavam matriculados na referida instituição de ensino, que apresentaram idade inferior a 18 anos e não consentiram em assinar o Termo de Consentimento Livre e Esclarecido (TCLE).

O QRM é constituído por questões fechadas com informações sobre sinais e sintomas relacionados a hipersensibilidades alimentares e/ou ambientais que ocorreram no organismo durante os últimos 30 dias. As questões foram preenchidas de modo subjetivo, através da pontuação dada pelos próprios participantes, conforme a escala de pontos presente no Quadro 1. 
Quadro 1 - Escala de pontos.

\begin{tabular}{|c|c|}
\hline Escala de Pontos & Frequência e efeito dos sintomas \\
\hline 0 & Nunca ou quase nuca teve o sintoma \\
\hline 1 & Ocasionalmente teve, efeito não foi severo \\
\hline 2 & Ocasionalmente teve, efeito foi severo \\
\hline 3 & Frequentemente teve, efeito não foi severo \\
\hline 4 & Frequentemente teve, efeito foi severo \\
\hline
\end{tabular}

Fonte: Costa DAL, et al., 2019.

A disbiose intestinal foi analisada por meio da pontuação total do QRM, conforme a interpretação presente no Quadro 2, e da seção específica do trato gastrointestinal. Segundo a avaliação sugerida pelo QRM, a quantidade de número 4 registrados em uma única seção indicam a presença de hipersensibilidade alimentar e/ou ambiental, bem como pontuações iguais ou acima de 10 pontos em uma seção específica do questionário. Portanto, dados estatísticos foram destacados para sintomas gastrointestinais, assim como outras seções do questionário, para análise da provável presença de disbiose intestinal e seus aspectos fisiopatológicos.

Quadro 2 - Interpretação do Questionário de Rastreamento Metabólico.

\begin{tabular}{|c|l|}
\hline Pontuação & \multicolumn{1}{c|}{ Interpretação } \\
\hline$<20$ pontos & Pessoas saudáveis, com menor chance de terem hipersensibilidade. \\
\hline$>30$ pontos & Indicativo de existência de hipersensibilidade \\
\hline$>40$ pontos & Absoluta certeza da existência de hipersensibilidade \\
\hline$>100$ pontos & $\begin{array}{l}\text { Pessoas com saúde muito ruim - alta dificuldade para executar tarefas diárias, pode } \\
\text { estar associado à presença de outras doenças crônicas e degenerativas }\end{array}$ \\
\hline
\end{tabular}

Fonte: Costa DAL, et al., 2019.

Para a tabulação dos dados foi utilizado o programa Microsoft Excel® versão 2016, que posteriormente foram compilados em gráficos para uma melhor visualização. Para análise descritiva dos dados foram estabelecidas prevalências, frequências absolutas e em percentuais.

A pesquisa foi realizada de acordo com as normas presentes na Portaria $n^{\circ} 466 / 2012$ do Conselho Nacional de Saúde, a qual regulamenta pesquisas envolvendo seres humanos, abordando o comprometimento com o sigilo, a confidencialidade e a privacidade exercida pelos pesquisadores aos participantes da pesquisa.

Em vista disso, todos os voluntários assinaram o Termo de Consentimento Livre e Esclarecido, no qual autorizaram a obtenção dos dados para a análise. O estudo foi aprovado pelo Comitê de Ética em Pesquisa do Centro Universitário de Brasília no dia 5 de dezembro de 2019, com Parecer Consubstanciado de número 3.747.750.

\section{RESULTADOS E DISCUSSÃO}

Conforme os dados apresentados na Tabela 1, compuseram a amostra do estudo 300 pessoas, sendo que $80 \%$ dos participantes são do gênero feminino. Os resultados obtidos a partir da soma total dos Questionários de Rastreamento Metabólico indicam que apenas 27 pessoas (9\%) possuem menores chances 
de terem hipersensibilidade, enquanto 172 pessoas $(57,33 \%)$ possuem hipersensibilidade, e 32 pessoas (10,67\%) possuem a saúde muito ruim.

Nessa pesquisa, somados os percentuais de pessoas com o escore maior que 40 e 100, foi observado que cerca de $68 \%$ dos participantes possuem com absoluta certeza hipersensibilidade de acordo com a interpretação do QRM.

Resultado semelhante foi obtido no estudo de Costa DAL, et al. (2019), no qual $74 \%$ da população analisada obteve escore maior que 40 e 100, ou seja, o número de pessoas com hipersensibilidade também abrange mais da metade da população estudada.

Tabela 1 - Resultado da pontuação final da aplicação do QRM.

\begin{tabular}{ccccccc}
\hline \multirow{2}{*}{ Faixa etária } & \multicolumn{2}{c}{ Feminino } & \multicolumn{2}{c}{ Masculino } & \multicolumn{2}{c}{ Total } \\
\cline { 2 - 7 } & $\mathbf{N}$ & $\%$ & $\mathbf{N}$ & $\%$ & $\mathbf{N}$ & $\%$ \\
\hline$<20$ pontos & 17 & 5,67 & 10 & 3,33 & 27 & 9,00 \\
20 a 30 pontos & 27 & 9,00 & 14 & 4,67 & 41 & 13,67 \\
31 a 40 pontos & 23 & 7,67 & 5 & 1,67 & 28 & 9,33 \\
41 a 100 pontos & 144 & 48,00 & 28 & 9,33 & 172 & 57,33 \\
$>100$ pontos & 29 & 9,67 & 3 & 1,00 & 32 & 10,67 \\
\hline Total & 240 & 80,00 & 60 & 20,00 & 300 & 100,00
\end{tabular}

Legenda: As pontuações de 20 a 30 não são interpretados pelo QRM, no entanto, elas foram consideradas nos resultados para que não haja erro.

Fonte: Vieira GC e Castro FFS, 2020.

A predominância do gênero feminino nesse estudo, que corresponde a $80 \%$, corrobora com a pesquisa realizada por Melo B e Oliveira $\mathrm{R}$ (2018), no qual o QRM foi preenchido em sua maioria pela população feminina, com representação de $83,51 \%$.

Essa preponderância se deve ao fato de o estudo ter sido realizado com estudantes da área da saúde que são em sua maioria do referido gênero. Tais evidências também justificam o fato de a população masculina apresentar porcentagem menor que a feminina em relação a hipersensibilidade, com 10,33\%, a pesar de representar igualmente um número significativo dentro da população masculina estudada.

O presente estudo considerou como portadores de disbiose intestinal os participantes que obtiveram escore maior ou igual a 10 na seção do trato digestório, ou seja, apenas os indivíduos que apresentaram sintomas característicos desse desequilíbrio intestinal, equivalente a cerca de $29 \%(n=87)$ da amostra total de indivíduos.

Esta análise difere de vários estudos já realizados, como as pesquisas realizadas por Galdino JJ, et al. (2016) e por Costa DAL, et al. (2019), pois ambas consideraram como risco para disbiose intestinal os indivíduos que obtiveram no somatório total um escore maior que 100 , ou seja pessoas com absoluta certeza de hipersensibilidade e com a saúde muito ruim. Além disso, também possui discordância com a pesquisa de Melo B e Oliveira R (2018), a qual considerou como portadores de disbiose intestinal as pessoas que obtiveram mais de 30 , que correspondem aos indivíduos que talvez possuam hipersensibilidade, somadas aos participantes que obtiveram mais de 40 e 100 pontos.

Esse método de avaliação quantitativa de pessoas com disbiose intestinal se deve a uma análise prudente dos dados, já que a hipersensibilidade possui outros gatilhos além da disbiose, como fatores propriamente genéticos e moleculares, bem como a atopia, por exemplo. Portanto, não é correto inferir que a 
hipersensibilidade esteja relacionada em todos os casos com a disbiose ou que seja uma consequência desta, já que, além de possuir outros agentes propulsores, também pode ser a causa dessa desordem intestinal, pois em alguns casos a resposta imunológica pode ser direcionada a bactérias comensais e acarretar em desequilíbrio da microbiota benéfica do intestino (BASU S e BANIK B, 2018; ABBAS A, et al., 2019).

Todos os indivíduos que compõe o percentual de $29 \%$ com sinais e sintomas característicos de disbiose intestinal também constituem o grupo de pessoas de 68\% que possuem, com absoluta certeza, hipersensibilidade. Esse fato está associado a interação entre o sistema imunológico e o intestino, representada pelo tecido linfoide associado a esse órgão, conhecido como tecido linfoide associado ao intestino (GALT), parte proeminente do tecido linfóide associado à mucosa (MALT) que representa cerca de $70 \%$ de todo o sistema imunológico. Os antígenos quando se encontram no lúmen intestinal são direcionados para o GALT a partir do epitélio e não através do sistema linfático ou sanguíneo, como ocorre nos órgãos linfoides secundários (GONÇALVES JL, et al., 2016; DELGOBO M, et al., 2019).

Em um estado de disbiose intestinal, ocorre um declínio das bactérias benéficas e consequente predomínio de bactérias patogênicas com aumento na produção de toxinas que são absorvidas pelo trato intestinal. Esses microrganismos prejudiciais, juntamente com os subprodutos formados, são capazes de causar danos no epitélio intestinal. Dessa forma, pela lesão da integridade epitelial, partículas presentes no lúmen intestinal tem contato com o GALT e o sistema imunológico as reconhece como invasoras, ocasionando uma desproporção T helper.

Com essa desproporção há o aumento dos níveis de Th17 e desequilíbrio da relação entre Th1 e Th2, o que induz a uma maior secreção de citocinas Th2, como a interleucina (IL)-4, IL-5 e IL-13 e estimula uma maior produção de imunoglobulina $\mathrm{E}$ ( $\mathrm{lgE})$, acarretando, assim, em respostas de caráter inflamatório e em quadros de hipersensibilidade (TOOR D, et al., 2019). Destaca-se que a disbiose intestinal possui sintomas que indicam facilmente a desordem, como diarreia, gases, prisão de ventre e cólicas frequentes (LOPES CLR, et al., 2017).

Desse modo, foram estabelecidos dados estatísticos para os sinais e sintomas da seção do trato gastrointestinal das 87 pessoas que obtiveram o escore maior que 10 nessa seção. Como pode ser observado no Figura 1, obtiveram destaque os sintomas de dor estomacal/intestinal, com 33,33\%, e abdômen distendido, 25,28\%, seguido por arrotos e/ou gases e azia com 22,98\%. Náuseas/vômitos, diarreia e constipação tiveram pontuação de menor frequência e intensidade.

Figura 1 - Sintomas mais frequentes e intensos da seção do trato gastrintestinal ( $n=87)$.

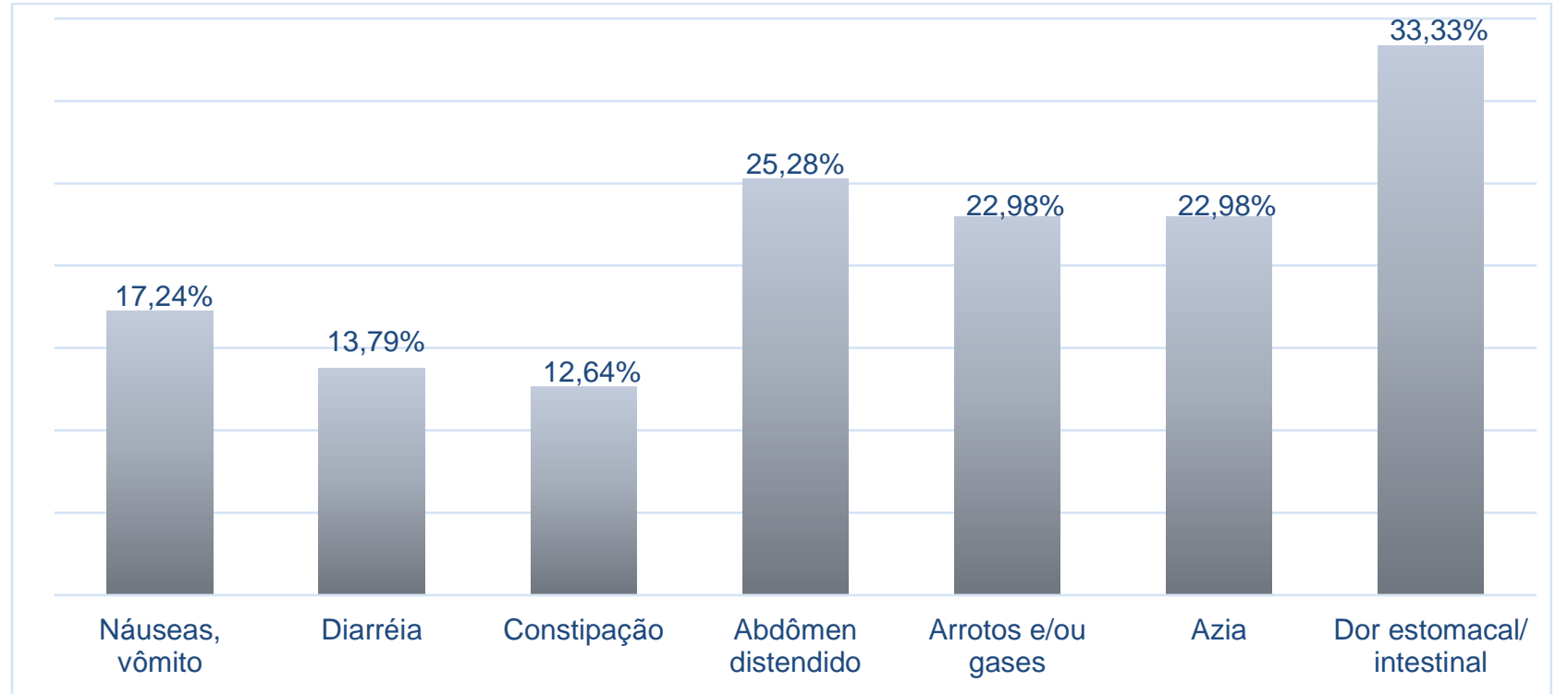

Fonte: Vieira GC e Castro FFS, 2020. 
Os dados apresentados corroboram com o estudo realizado por Lopes CLR, et al. (2017), no qual o sintoma mais prevalente foi dor estomacal/intestinal, com presença em $100 \%$ dos pacientes analisados, também seguido por abdômen distendido, arroto e/ou gases e azia, todos com $36 \%$, sendo que náuseas/vômitos, diarreia e constipação foram os sintomas menos frequentes.

Os sintomas característicos de disbiose influenciam-se mutuamente, pois, quando ocorre alterações na comunidade bacteriana e há o aumento de bactérias fermentadoras no lúmen intestinal, há a elevação da fermentação e consequentemente aumento da produção dos gases.

O acúmulo de gases nas alças intestinais leva a uma distensão abdominal e pode causar compressão nos órgãos da cavidade abdominal acarretando em quadros de dor e incomodo. Além disso, a dor também pode ser em decorrência de uma microinflamação da mucosa intestinal. Nestas circunstâncias, a absorção intestinal se apresentará diminuída, podendo resultar em quadros de constipação (SANTOS T e VARAVALLO $M, 2011)$.

A Tabela 2 apresenta a quantidade de indivíduos com sintomas de disbiose intestinal que obtiveram 0 escore igual ou maior que 10 em cada seção do QRM e a Tabela 3 expõe os sintomas mais prevalentes em cada seção que receberam com mais regularidade a pontuação 4, relativa a maior frequência e severidade.

Pode-se verificar que das 87 pessoas, 49,43\% sentem sintomas frequentes e severos na seção do nariz, com ênfase para os sinais de corrimento nasal, $26,44 \%$, e ataques de espirros, $22,99 \% ; 48,28 \%$ na seção voltada às emoções, com destaque para ansiedade, 45,98\%, e irritabilidade, 27,59\%; na parcela que se refere a sintomas mentais, $47,13 \%$, em evidência o sintoma de memória ruim, 20,69\%; a porção de energia e atividade foi relatada por 29,89\%, com realce para o sinal de fadiga, $22,99 \%$; e $21,84 \%$ possuem com intensidade sintomas relacionados a pele, com destaque para perda de cabelo, 16,09\%, e acne 11,49\%.

Tabela 2 - Total de indivíduos que obtiveram escore maior ou igual a 10 pontos por seção ( $n=87)$.

\begin{tabular}{ccc}
\hline Seções & $\mathbf{N}$ & $\%$ \\
\hline Cabeça & 11 & 12,64 \\
Olhos & 11 & 12,64 \\
Ouvidos & 1 & 1,15 \\
Nariz & 43 & 49,43 \\
Boca/garganta & 7 & 8,05 \\
Pele & 19 & 21,84 \\
Coração & 5 & 5,75 \\
Pulmões & 4 & 4,60 \\
Articulações/músculos & 16 & 18,39 \\
Energia/Atividade & 26 & 29,89 \\
Mente & 41 & 47,13 \\
Emoções & 42 & 48,28 \\
Outros & 5 & 5,75 \\
\hline
\end{tabular}

Fonte: Vieira GC e Castro FFS, 2020. 
Tabela 3 - Sintomas mais frequentes e intensos presentes nas demais seções $(n=87)$.

\begin{tabular}{|c|c|c|c|}
\hline Seções & Sintomas & $\mathbf{N}$ & $\%$ \\
\hline \multirow{2}{*}{ Cabeça } & Dor de cabeça & 19 & 21,84 \\
\hline & Insônia & 15 & 17,24 \\
\hline Olhos & Lacrimejantes & 10 & 11,49 \\
\hline Ouvidos & Zunido & 3 & 3,45 \\
\hline \multirow{2}{*}{ Nariz } & Corrimento nasal & 23 & 26,44 \\
\hline & Ataques de espirros & 20 & 22,99 \\
\hline Boca & Dor de garganta e rouquidão & 5 & 5,75 \\
\hline \multirow{2}{*}{ Pele } & Perda de cabelo & 14 & 16,09 \\
\hline & Acne & 10 & 11,49 \\
\hline \multirow{2}{*}{ Coração } & Batidas rápidas demais & 6 & 6,90 \\
\hline & Dor no peito & 5 & 5,75 \\
\hline \multirow{2}{*}{ Pulmões } & Pouco fôlego & 5 & 5,75 \\
\hline & Asma, bronquite & 4 & 4,60 \\
\hline \multirow{2}{*}{$\begin{array}{c}\text { Músculos } \\
\text { Articulações }\end{array}$} & Fraqueza & 20 & 22,99 \\
\hline & Dores musculares & 9 & 10,34 \\
\hline \multirow{2}{*}{ Energia } & Fadiga & 20 & 22,99 \\
\hline & Dificuldade em relaxar & 19 & 21,84 \\
\hline \multirow{2}{*}{ Mente } & Memória ruim & 18 & 20,69 \\
\hline & Concentração ruim & 16 & 18,39 \\
\hline \multirow{2}{*}{ Emoções } & Ansiedade & 40 & 45,98 \\
\hline & Irritabilidade & 24 & 27,59 \\
\hline \multirow{2}{*}{ Outros } & Urina com frequência & 10 & 11,49 \\
\hline & Frequentemente doente & 8 & 9,20 \\
\hline
\end{tabular}

Fonte: Vieira GC e Castro FFS, 2020.

Conforme apresentado na tabela 2, dentre as 87 pessoas com sinais e sintomas característicos de disbiose, $49,43 \%$ apresentaram pontuação igual ou maior que 10 pontos na seção do nariz, apresentando em sua maioria sinais e sintomas característicos de rinite alérgica, uma inflamação da mucosa de revestimento nasal, mediada pelo aumento da produção de lgE em consequência à exposição a alérgenos, caracterizada pela presença de obstrução nasal, rinorreia, espirros e hiposmia, podendo evoluir para um quadro de sinusite (ABORL-CCF, 2012).

A pesquisa realizada por Nogueira JCR e Goncalves MCR (2011), verificou, através de uma revisão sobre o uso de probióticos no tratamento da rinite alérgica, que o uso destes diminuem de maneira considerável as formas graves da rinite alérgica e promovem a melhora da resposta imunológica.

Como as bactérias da microflora intestinal atuam no balanço Th1/Th2 e a linhagem T helper 2 estimula células que participam da reação alérgica, como linfócitos $B$ secretores de $\lg E$, eosinófilos e mastócitos, 0 predomínio da linhagem Th2 em relação a Th1 está relacionado ao desenvolvimento da renite alérgica.

Os sintomas relacionados às emoções, relatados por $48,28 \%$ dos participantes com disbiose, possuem estrita ligação com a microbiota intestinal, pois esta auxilia o desenvolvimento e a função do cérebro, e este, por sua vez, interage com as bactérias intestinais por meio de vias neuroimunes, neuroendócrinas e do sistema nervoso. Esse sistema de comunicação bidirecional é chamado de eixo cérebro-intestino-microbiota (SILVESTRE CMRF, 2016). Através deste sistema de comunicação bidirecional, os sinais do cérebro podem influenciar os efeitos fisiológicos do intestino, incluindo motilidade, secreção e função imunológica, e as mensagens do intestino podem influenciar a função cerebral no que diz respeito à regulação dos reflexos e estados de humor (O'MAHONY SM, et al., 2011). 
O desequilíbrio da microbiota intestinal com o predomínio de microrganismos patogênicos leva a uma interferência na produção de citocinas inflamatórias e anti-inflamatórias, o que ocasiona inflamação do epitélio intestinal e aumenta a sua permeabilidade, permitindo que antígenos bacterianos, peptídeos neuroativos e lipopolissacarídeos (LPS), entrem em contato com vias neurais, modulando diretamente o seu funcionamento.

Os LPS ativam receptores toll-like da micróglia e provocam a liberação direta de citocinas inflamatórias no sistema nervoso central, onde a resposta inflamatória pode afetar as vias metabólicas e moleculares, interferindo nos neurocircuitos que regulam o comportamento, especialmente comportamentos relativos à fadiga, relatada por $22,99 \%$ dos participantes, diminuição da motivação, prevenção e alarme (ansiedade), os quais caracterizam vários distúrbios neuropsiquiátricos, incluindo depressão (MILLER A e RANSON C, 2016; YARANDI SS, et al., 2016).

Dentre os sintomas mentais relatados por $47,13 \%$, o sintoma de memória ruim, 20,69\%, também possui relação com a ação do LPS. Esse, quando presente em grandes quantidades no intestino, pode representar um fator importante para a inflamação sistêmica e comprometimento da memória, por interromper circuitos neurais específicos no hipocampo, estando relacionado da mesma forma com a progressão da doença de Alzheimer (LUKIW W, 2016).

Além disso, sabe-se que a microbiota intestinal pode secretar uma série de neurotransmissores, como por exemplo, o Lactobacillus spp. produz GABA e acetilcolina; Bifidobacterium spp. Produz GABA; Escherichia spp. produz noradrenalina e serotonina; Bacillus spp. produz noradrenalina e dopamina; Candida spp., Streptococcus spp. e Enterococcus spp. produzem serotonina (CRYAN J e DINAN $\mathrm{T}, 2012)$.

As seções com sintomas relacionados a pele, relatados por $21,84 \%$ dos participantes com disbiose como severos, possui relação com alterações na permeabilidade intestinal e com o sistema nervoso central. Os metabólitos da microbiota intestinal que tem acesso à corrente sanguínea, acumulam-se na pele e interrompem a homeostase desta, podendo provocar queda de cabelo, relatada por $16,09 \%$ dos participantes.

Ainda, a complexa conexão com a acne, relatada por $11,49 \%$ dos universitários, está associada frequentemente a comorbidades psicológicas. Os estressores psicológicos estimulam a microbiota intestinal a produzir diferentes neurotransmissores e células enteroendócrinas a liberar neuropeptídeos.

Esses neurotransmissores não apenas aumentam a permeabilidade intestinal, mas também acessam diretamente a circulação através da barreira intestinal comprometida, resultando em efeitos sistêmicos, o que inclui a acne (JENA A e SAHOO S, 2016; O'NEILL CA, et al., 2016; VAUGHN A, et al., 2017).

\section{CONCLUSÃO}

Há uma baixa prevalência de disbiose intestinal entre os participantes da pesquisa, equivalente a $29 \%$, no entanto, as pessoas que compõe esse percentual apresentaram de forma significativa sintomas relacionados a quadros alérgicos, desequilíbrios emocionais e mentais, além da presença de sinais incômodos no tegumento. Essas evidências são atribuídas ao fato de que a microbiota intestinal é fundamental para a homeostase dos seres humanos, o que implica a influência que exerce sobre a digestão alimentar, sistema nervoso, comportamento do indivíduo e o desenvolvimento do sistema imunológico. Portanto, quando um indivíduo se encontra em um estado de disbiose, é necessário considerar que ele pode apresentar além de distúrbios no trato gastrintestinal, desequilíbrios extra intestinais. Assim, a associação entre a disbiose intestinal e as patologias abordadas é uma fonte importante de diagnóstico que torna a manipulação da microbiota uma opção terapêutica potencial para o tratamento desses distúrbios.

\section{AGRADECIMENTOS}

Os autores gostariam de agradecer ao professor Dr. Eduardo Cyrino de Oliveira Filho, à Ana Beatriz da Silva Baptista Germano, à Vitória Cavalcante Cardoso e à Livia Causin Vieira pelo auxílio durante a elaboração da pesquisa. 


\section{REFERÊNCIAS}

1. ABBAS A, et al. Imunologia celular e molecular. 9nd ed. Rio de Janeiro: Elsevier, 2019.

2. ABORL-CCF (Associação Brasileira de Otorrinolaringologia e Cirurgia Cérvico-Facial). III Consenso Brasileiro sobre Rinites. Brazilian Journal of Otorhinolaryngology, 2012; 75 (6): 6-41.

3. BASU S, BANIK B. Hypersensitivity: An Overview. Current Research in Immunology, 2018; 2(1): 105.

4. BOWE W, LOBERG K. Cuidar da Pele de Dentro para Fora: O Poder da Flora Intestinal na Saúde da Sua Pele. 2. Ed. Portugal: 20|20, 2018.

5. CASTAÑEDA C. Microbiota intestinal e saúde infantil. Revista Cubana de Pediatria, 2018; 90(1): 1-18.

6. COSTA DAL, et al. Prevalência de sinais e sintomas de disbiose intestinal em obesos atendidos em uma instituição de ensino de Brasília-DF. Revista Brasileira de Obesidade, Nutrição e Emagrecimento, 2019; 13(80): 488-497.

7. CRYAN J, DINAN T. Mind-altering microorganisms: the impact of the gut microbiota on brain and behavior. Nature Reviews Neuroscience, 2012; 13: 701-712.

8. CRYAN J, O'MAHONY S. The microbiome-gut-brain axis: from bowel to behavior. Journal of Neurogastroenterology and Motility, 2011; 23(3): 92-187.

9. DELGOBO M, et al. Gut: Key Element on Immune System Regulation. Brazilian Archives of Biology and Technology, 2019; 62(5): 1-14.

10. FORSYTHE P, et al. Mood and gut feelings. Brain, behavior, and immunity. 2010; 24(1): 9-16.

11. FRANCINO M. Early development of the gut microbiota and imune health. Pathogens. 2014; 3(3): 769-790.

12. GALDINO J, et al. Questionário de rastreamento metabólico voltado a disbiose intestinal em profissionais de enfermagem. Revista Brasileira de Obesidade, Nutrição e Emagrecimento, 2016; 10(57): 117-122.

13. GONÇALVES J, et al. Bases do sistema imunológico associado à mucosa intestinal. In: ORIÁ, R.; BRITO, G. Sistema digestório: integração básico-clínica. 1nd ed. São Paulo: Edgard Blucher, 2016; 369-387p.

14. GUARNER F, et al. World Gastroenterology Organization Global Guidelines: Probiotics and prebiotics. Journal of Clinical Gastroenterology, 2012; 46(6): 468-481.

15. HUGON P, et al. A comprehensive repertoire of prokaryotic species identified in human beings. The Lancet Infectious Diseases, 2015; 15: 1211-1219.

16. JANDHYALA SM, et al. Role of the normal gut microbiota. World Journal of Gastroenterology, 2015; $21(29): 8787-803$.

17. JENA A, SAHOO S. Evaluation of associated anxiety and depression in patients with acne vulgaris: a hospital based clinico-epidemiological study. Indian journal of research, 2019; 5(10): 82-82.

18. KNIGHTS D, et al. Advances in inflammatory bowel disease pathogenesis: linking host genetics and the microbiome. Gut, 2013; 62(10): 1505-1510.

19. LOPES CLR, et al. A prevalência de sinais e sintomas de disbiose intestinal em pacientes de uma clínica em TeresinaPI. C\&D-Revista Eletrônica da FAINOR, 2017; 10(3): 280-292.

20. LUKIW W. Bacteroides fragilis Lipopolysaccharide and Inflammatory Signaling in Alzheimer's Disease. Frontiers in Microbiology, 2016; 26(7): 1544.

21. MELO B, OLIVEIRA R. Prevalência de disbiose intestinal e sua relação com doenças crônicas não transmissíveis em estudantes de uma instituição de ensino superior de Fortaleza-CE. Revista Brasileira de Obesidade, Nutrição e Emagrecimento, 2018; 12(74): 767- 775.

22. MILLER A, RAISON C. The role of inflammation in depression: from evolutionary imperative to modern treatment target. Nature reviews immunology, 2016; 16(1): 22-34.

23. NOGUEIRA JCR, GONCALVES MCR. Uso de probióticos na rinite alérgica. Brazilian journal of otorhinolaryngology, $2011 ; 77(1): 129-134$.

24. OLIVARES M, et al. Oral administration of Bifidobacterium longum CECT 7347 ameliorates gliadin-induced alterations in liver iron mobilisation. The British journal of nutrition, 2013; 110(10): 1828-1836.

25. O'MAHONY S, et al. Maternal separation as a model of brain-gut axis dysfunction. Psychopharmacology, 2011;214(1): 71-88.

26. O'NEILL C, et al. The gut-skin axis in health and disease: a paradigm with therapeutic implications. Bioessays, 2016; 38(11): 1167-1176.

27. PAIXÂO LA, CASTRO FFS. Colonização da microbiota intestinal e sua influência na saúde do hospedeiro. Universitas: Ciências da Saúde, 2016; 14(1): 85-96.

28. PEREIRA IG, FERRAZ IAR. Suplementação de glutamina no tratamento de doenças associadas à disbiose intestinal. Revista Brasileira de Saúde Funcional, 2017; 1(1): 46.

29. QIN J, et al. A human gut microbial gene catalogue established by metagenomic sequencing. Nature, 2010; 464(7285): 59-65.

30. SANTOS T, VARAVALLO M. A importância de probióticos para o controle e/ou reestruturação da microbiota intestinal. Revista Científica do ITPAC, 2011; 4(1): 40-49.

31. SILVESTRE CMRF. O diálogo entre o cérebro e o intestino: qual o papel dos probióticos? Revisão de literatura. Dissertação (Mestrado Integrado em Medicina) - Faculdade de Medicina da Universidade de Lisboa, Lisboa, Portugal, 2016.

32. TOOR D, et al. Dysbiosis Disrupts Gut Immune Homeostasis and Promotes Gastric Diseases. International journal of molecular sciences, 2019; 20(10): 2432.

33. VAUGHN A, et al. Skin-gut axis: the relationship between intestinal bacteria and skin health. World Journal of Dermatology, 2017; 6(4): 52-58.

34. YARANDI SS, et al. Modulatory effects of gut microbiota on the central nervous system: how gut could play a role in neuropsychiatric health and diseases. Journal of neurogastroenterology and motility, 2016; 22, 201-212. 